\title{
Feel your food : the influence of tactile sensitivity on picky eating in children
}

Citation for published version (APA):

Nederkoorn, C., Jansen, A., \& Havermans, R. C. (2015). Feel your food : the influence of tactile sensitivity on picky eating in children. Appetite, 84, 7-10. https://doi.org/10.1016/j.appet.2014.09.014

Document status and date:

Published: 01/01/2015

DOI:

10.1016/j.appet.2014.09.014

Document Version:

Publisher's PDF, also known as Version of record

Document license:

Taverne

Please check the document version of this publication:

- A submitted manuscript is the version of the article upon submission and before peer-review. There can be important differences between the submitted version and the official published version of record.

People interested in the research are advised to contact the author for the final version of the publication, or visit the DOI to the publisher's website.

- The final author version and the galley proof are versions of the publication after peer review.

- The final published version features the final layout of the paper including the volume, issue and page numbers.

Link to publication

\footnotetext{
General rights rights.

- You may freely distribute the URL identifying the publication in the public portal. please follow below link for the End User Agreement:

www.umlib.nl/taverne-license

Take down policy

If you believe that this document breaches copyright please contact us at:

repository@maastrichtuniversity.nl

providing details and we will investigate your claim.
}

Copyright and moral rights for the publications made accessible in the public portal are retained by the authors and/or other copyright owners and it is a condition of accessing publications that users recognise and abide by the legal requirements associated with these

- Users may download and print one copy of any publication from the public portal for the purpose of private study or research.

- You may not further distribute the material or use it for any profit-making activity or commercial gain

If the publication is distributed under the terms of Article $25 \mathrm{fa}$ of the Dutch Copyright Act, indicated by the "Taverne" license above, 
Research report

\title{
Feel your food. The influence of tactile sensitivity on picky eating in children
}

\author{
Chantal Nederkoorn *, Anita Jansen, Remco C. Havermans \\ Faculty of Psychology and Neuroscience, Maastricht University, Maastricht, The Netherlands
}

\section{A R T I C L E I N F O}

\section{Article history:}

Received 9 April 2014

Received in revised form 22 August 2014

Accepted 18 September 2014

Available online 26 September 2014

\section{Keywords:}

Selective eating

Food texture

Tactile sensitivity

Children

\begin{abstract}
A B S T R A C T
Children who are very picky in eating frequently refuse the intake of foods. This rejection is not only based on the evaluation of taste, but also on tactile qualities of foods. It matters whether food is crispy or slimy, consistent, or with bits and pips. It is hypothesised that children who are more sensitive to touch and dislike the feel of various tactile stimuli in general, are also more dismissive of tactile stimulation in their mouth and therefore more selective in their eating. In the present study, 44 children between the ages of 4 and 10 were asked to feel different tactile stimuli with their hands and to taste different foods. Results showed a significant positive correlation between the evaluations of the two modalities, especially for the younger subjects. This suggests that tactile sensitivity might play a role in the acceptance of food. Future research could explore if training children to tolerate more tactile stimuli would also increase their appreciation of a wider variety of foods.
\end{abstract}

(c) 2014 Elsevier Ltd. All rights reserved.

\section{Introduction}

A common problem that a majority of parents face in child rearing is that children do not want to eat the food their parents present them. Parents often report their toddlers spitting out food during feeding and pushing or throwing foods away (Lewinsohn et al., 2005). This problem can range from refusing a single food item to the rejection of complete food categories. Children are considered more picky or selective in eating when they accept a smaller variety of food items presented by their caregivers. (Dovey, Staples, Gibson, \& Halford, 2008; Jacobi, Agras, Bryson, \& Hammer, 2003). The rejected food can either be familiar or novel. The unwillingness to try novel foods is also called 'food neophobia'. This phenomenon can be considered part of picky eating (Dovey et al., 2008). Pickiness has disadvantages because it is related to insufficient vegetable and fruit intake and a healthy diet requires varied food intake (Jacobi et al., 2003). In an extreme form, pickiness in eating can even lead to avoidant/restrictive food intake disorder, as described in DSM-5 (American Psychiatric Association, 2013). This disorder is characterised by the failure to meet appropriate nutritional or energy needs, caused by lack of interest in food, rejection of food based on its sensory characteristics or concern about aversive consequences of eating.

To some extent, pickiness in eating is a normal developmental phase. Pickiness normally reaches its peak between 3.5 and 5.5 years and then reduces gradually. However, the range of pickiness among

\footnotetext{
* Corresponding author.

E-mail address: c.nederkoorn@maastrichtuniversity.nl (C. Nederkoorn).
}

children is large and almost $20 \%$ of children between 8 and 12 can still be considered picky eaters, meaning that the variety of their diets can be considered insufficient (Dovey et al., 2008; Jacobi, Schmitz, \& Agras, 2008). Despite its developmental dynamic, pickiness appears to be a stable trait: more picky eating early in life predicts more picky eating in adulthood, especially when considering the intake of fruits and vegetables (Nicklaus, Boggio, Chabanet, \& Issachou, 2005; Skinner, Carruth, Bounds, \& Ziegler, 2002).

The most obvious reason why children do not want to eat a certain food is because they do not like the taste of it (Gibson, Wardle, \& Watts, 1998). However, children do not only reject food because of the taste, they can also dislike the texture, temperature or colour of the food. When considering tactile qualities, in general, people have a dislike for tough, lumpy and slimy food, probably because those foods are more difficult to manipulate in the mouth while eating (Szczesniak, 2002). In addition, foods containing hard particles or pips and bits are generally disliked, perhaps because of the danger of choking or contamination of the food (Szczesniak, 2002; Wardle \& Cooke, 2008). In general, people like foods that are crispy or crunchy, although this also depends on the type of food and expectancies people have (Szczesniak, 2002). For instance, people expect an apple to be firm and crispy and hence a soft, mealy apple is experienced negatively. But for a cake, it is totally acceptable to be soft and to have a spongy texture. Indeed, a crispy and juicy piece of cake would probably be disliked. Zeinstra and colleagues prepared two foods (carrots and beans) at six different ways, analysed how this influenced different attributes of food and how this was related to the preference of children. They found that preparation methods that increased crunchiness were liked better, whereas preparations that increased granular texture or made the food fall 
apart were disliked. However, the two most liked preparation methods were also the most familiar ones, so familiarity and expectancy might also have played a role (Zeinstra, Koelen, Kok, \& de Graaf, 2010).

While some children easily accept many different tactile qualities of food, others might be quite fastidious. One factor affecting the acceptance of different tactile qualities is how sensitive children are to touch. Tactile sensitivity can be conceptualised both as having better tactile perception and as stronger affective responding to tactile stimulation (Cascio et al., 2008; Parush, Sohmer, Steinberg, \& Kaitz, 2007). More tactile sensitive children who strongly dislike particular tactile sensations, like the feel of sand or grass, or labels and seams in clothing, appear to be more sensitive to touch in their mouth and therefore to textures of food as well (Dunn, 1997). This might suggest that sensitivity to touch contributes to picky eating, and indeed some studies support this assumption. For instance, a group of children clinically diagnosed with tactile defensiveness (children who display an overreaction to tactile stimulations) rejected more foods, ate fewer vegetables and refused more often to eat new foods, compared to healthy children (Smith, Roux, Naidoo, \& Venter, 2005). Moreover, in a sample of normal healthy children between 2 and 5 years old, parental reports of tactile sensitivity correlated both with fruit and vegetable intake and with parental reported food neophobia (Coulthard \& Blissett, 2009). In addition, in a study with children between 5 and 10 years old, not only a relation was found between taste sensitivity and selective eating, but also between tactile sensitivity and selective eating (Farrow \& Coulthard, 2012). Again, this indicates that if children tend to dislike the feeling of several stimuli more, they might also dislike specific tactile qualities in their mouth and therefore dislike and refuse specific foods.

A clear limitation of the abovementioned studies is that they were all based on parental report. It is possible that this introduced a bias; that is, overly concerned parents might be inclined to overly report both the tactile sensitivity and the selective eating in their children. Moreover, picky eating in children is related to more conflicts during meal times and struggles for control (Lewinsohn et al., 2005) and to preparation of special meals (Mascola, Bryson, \& Agras, 2010). This could result at different eating behaviour at home then during an objective taste test in a lab.

In the study of Lukasewycz and Mennella (2012), a behavioural measure of tactile sensitivity was used. It was measured in children and mothers if lingual tactile acuity - the ability to identify raised alphabetical letters with the tips of their tongues - was related to preferences in food textures, pickiness and food neophobia. No such a relation was found, which suggests that picky eaters are not better in tactile perception. It is however possible that although their perceptual abilities are not different, their appreciation of tactile stimuli is.

Therefore, in the present study, the relation between picky eating and appreciation of tactile stimuli in children was measured with behavioural tests. Picky eating was measured by presenting 10 food items, with different structures, textures and temperatures and willingness to taste the food items and liking of the different foods was measured. The children were also asked to feel 10 tactile stimuli, with different structures, textures and temperatures and liking of the stimuli was measured, as an index of tactile sensitivity. Because pickiness in eating is related to age, we expect to find a more pronounced relation between preferences for textures and tastes in the younger children.

\section{Method}

Participants

All parents from children in grades 2 to 5 of two elementary schools in The Netherlands received an informed consent and two questionnaires, which the parents could return if they gave their permission. Forty-seven children with permission from their parents were asked to participate. Three children were excluded because they had some type of food allergy. The remaining 44 children, 24 girls and 20 boys, were between 4 and 10 years old (mean $=7.3$, $\mathrm{SD}=1.9$ ).

\section{Materials}

In the behavioural test of picky eating, each child was offered 10 different kinds of food to taste: banana, warm green tea, rice milk, sparkling water, raw carrot, ice cubes, peas, jelly, shrimp crackers and a toffee, all presented in equal white plastic bowls, $\varnothing 10 \mathrm{~cm}$. The food items were chosen to include different textures and temperatures, like smooth, crispy, slimy, rough, hard, soft, hot and cold. Two scores were derived from this test. First, it was measured how many food items a child was willing to taste, which could range from 0 to 10 . A child was considered less picky if he/she refuses less food items. Second, the children were asked to evaluate the food items. If a child has a higher overall liking of the food items, he/she is also considered less picky. If a child refused to taste a food item he/she was scored 0 , when a child did taste the food, he/she had to indicate whether he/she liked it or not on a five-point scale, ranging from a smiling face (very pleasant; this corresponds to a score of 5) to an angry/sad face (very unpleasant; this corresponds to a score of 1$)$. At the start of the behavioural test, the scale was explained and when the child indicated understanding of the task, she/he was offered the 10 different kinds of food. The scores could range from 0 to 50 , higher scores mean that the child evaluated different foods more positively and is an index of less picky eating. The Cronbach alpha value of this measure was .56 .

In the behavioural test of tactile sensitivity, children were offered 10 different stimuli to touch with their hands. The stimuli (a velvet cloth, warm water, sugar, sanding paper, a stone, ice cubes, cookie dough, jelly, shrimp crackers and hair gel) were placed in plastic bowls, $\varnothing 10 \mathrm{~cm}$, inside 10 separate closed shoeboxes (with an opening for their hand). Again, the objects were chosen to include different textures and temperatures. The children indicated for every stimulus whether they found it pleasant to touch. The children first practiced with an open shoebox, with marbles in the bowl and then it was explained how the rating scale worked. The scale ranged from a smiling face (very pleasant to feel; this corresponded to a score of 5) to an angry/sad face (very unpleasant to feel; this corresponded to a score of 1 ), making it a five-point scale. Scores can range from 5 to 50, with higher scores indicating higher affective evaluation of the tactile stimuli, an index of less tactile sensitivity. The Cronbach alpha value of this behavioural test appeared .79.

\section{Questionnaires}

Parents were to rate the variety of food products their children liked, based on the method of Schreck, Williams, and Smith (2004). Parents were asked to rate if their children liked a food item (score 1 ) or not (score 0 ). This was asked for 50 different food items, categorised in five groups (fruits, vegetables, dairy products, grain products and protein-containing products). Scores can range from 0 to 50, with higher scores meaning the child is less picky in eating. The Cronbach alpha value, entering the five subcategories, was .76.

Further, parents were asked to fill out the Dutch translation of two subscales of the Short Sensory Profile (Dunn, 1999): sensitivity to taste, which consists of four questions, and processing tactile stimuli, which consisted of 18 questions. Each item was scored on a five-point scale. Higher scores mean lower taste/tactile sensitivity. The Cronbach alpha value of the taste subscale was .83 , of the tactile subscale .75 . 
Table 1

Mean scores and correlations between the dependent variables.

\begin{tabular}{|c|c|c|c|c|c|c|}
\hline & Mean (SD) & 2 & 3 & 4 & 5 & 6 \\
\hline $\begin{array}{l}\text { 1. Picky eating } \\
\text { (behavioural test: } \\
\text { number of foods tasted) }\end{array}$ & $9.0(1.3)$ & $.74^{* *}$ & $.30^{*}$ & $.35^{*}$ & $.40^{*}$ & .02 \\
\hline $\begin{array}{l}\text { 2. Picky eating } \\
\text { (behavioural test: } \\
\text { liking of food items) }\end{array}$ & $37.2(6.7)$ & & $.303^{*}$ & $.38^{*}$ & .21 & -.11 \\
\hline $\begin{array}{l}\text { 3. Tactile sensitivity } \\
\text { (behavioural test: } \\
\text { liking of tactile stimuli) }\end{array}$ & $36.7(7.1)$ & & & -.09 & -.02 & .17 \\
\hline $\begin{array}{l}\text { 4. Variety food products } \\
\text { Questionnaire }\end{array}$ & $38.6(7.3)$ & & & & $.51^{* *}$ & .01 \\
\hline $\begin{array}{l}\text { 5. Taste sensitivity } \\
\text { Subscale SSP }\end{array}$ & $3.89(.89)$ & & & & & .22 \\
\hline $\begin{array}{l}\text { 6. Processing tactile stimuli } \\
\text { Subscale SSP }\end{array}$ & $4.41(.32)$ & & & & & \\
\hline
\end{tabular}

\section{Procedure}

The study was approved by the Maastricht University, Faculty of Psychology and Neuroscience Ethical Committee. Children were tested individually and the order of the behavioural tests was counterbalanced. Afterwards they received a little present (a pencil or eraser) for their participation.

\section{Results}

The behavioural measures of picky eating both correlated significantly with affective evaluation of tactile stimuli (see Table 1).

Age did not correlate to picky eating (number of tasted foods: $r=-.07$; liking of foods: $r=.147, p=.34$ ) and only trend-significant with the evaluation of tactile stimuli $(r=-.262, p=.086)$. However, when the group was divided in a younger versus an older group, based on a median split (median $=91.5$ months, around 7.5 years), it appeared that the relation between picky eating and tactile sensitivity was present in the younger group $(n=22$, number of tasted foods: $r=.45, p=.037$; liking of food: $r=.49, p=.021$ ) but not in the older group ( $n=22$, number of tasted foods: $r=.14, p=.53$; liking of foods: $r=-.024, p=.92$; see Fig. 1 ).

Both measures of the behavioural test of picky eating correlated significantly to the parental ratings of variety of food intake of the children, but only the number of foods tasted correlated significantly to the parental rating of taste sensitivity (see Table 1).
The behavioural test of tactile sensitivity did not correlate to the parental questionnaire of processing tactile stimuli.

\section{Discussion of the}

In the present study we showed that behavioural measures of tactile sensitivity are correlated to picky eating in a sample of normal children, especially in the younger children between 4 and 7.5 years. This is in line with our model that a higher sensitivity to touch causes children to dislike the feel of particular foods in their mouth and therefore to dislike eating the foods. The fact that the relation was only confirmed in younger children suggests that the tactile qualities of food are more important in that age, perhaps because the dental and physical development makes it more difficult to manipulate food in their mouth (Szczesniak, 2002). Older children also have a longer learning history and might therefore incorporate more factors to base their preference on, which might make tactile qualities less important. It should also be noted that the present study has a small sample size, and replication, preferably with a larger sample size is warranted. Moreover, a longitudinal design, in which tactile sensitivity and picky eating is tested repeatedly in the same children, would inform us more about the development of the relations between tactile sensitivity and picky eating.

In the present study, we only measured affective evaluation of tactile stimuli as index for tactile sensitivity. Lukasewycz and Mennella (2012) found that tactile acuity in children was not related to food preference or picky eating. However, it is possible that other measures of tactile sensitivity, like threshold for touch, are related to food preferences. In would be interesting to measure several dimensions of tactile sensitivity and relate it to food preferences in children, in one study.

The behavioural tests only partly corresponded to the parental questionnaires. It is possible that children behave differently during an objective test at school compared to a home environment. At school, the presence of an unknown test leader and demand characteristics might influence behaviour, whereas at home different factors (like the wish for autonomy and parenting style) can play a role. In addition, the norm of parents (i.e. which tastes are normal for children) might differ, thereby influencing their conception of whether a child is picky/tactile sensitive or not. More research validating the behavioural tests is therefore advised.

The present cross-sectional design does not preclude alternative explanations. For example, it is possible that some children are more sensitive to all kinds of sensory stimulation, including not only touch and taste but extending to sounds, light, and smells. A general sensitivity would in that case explain the relation between sensitivity to taste and touch. This means future research should take
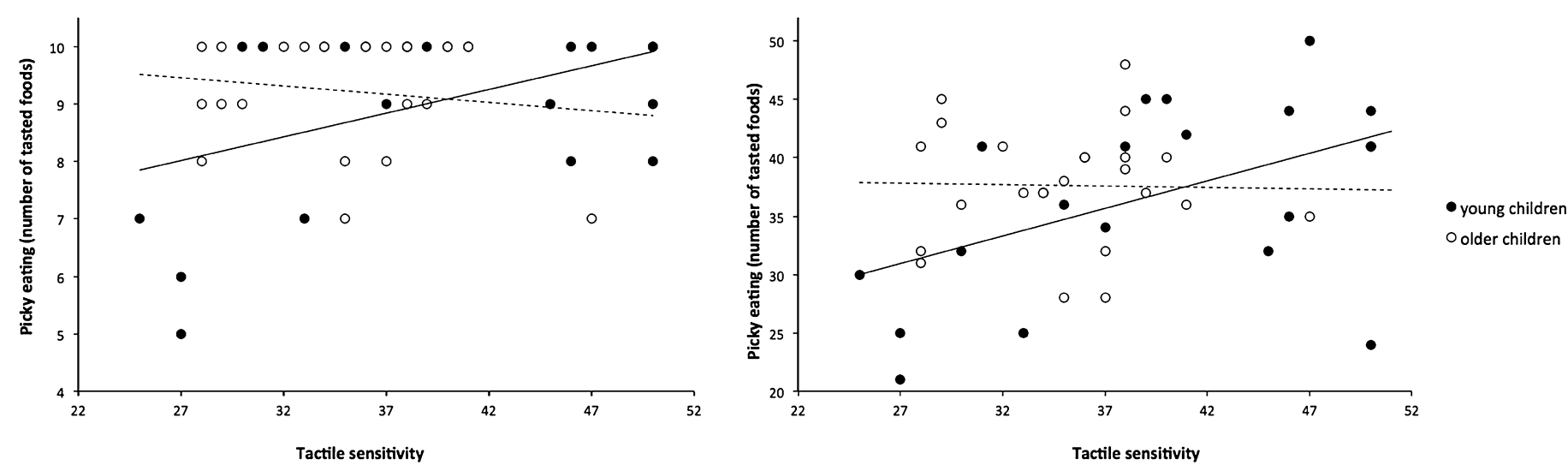

Fig. 1. Scatter plots and trend lines, showing the relation between tactile sensitivity and number of tasted foods (left panel) and liking of foods (right panel). 
more aspects (e.g., general sensitivity) into account, but also that a more experimental approach is warranted. For instance, one could manipulate the acceptance of tactile stimuli by repeated exposure (letting children touch different tactile stimuli by hand) and test if this influences acceptance of food items and reduces pickiness in eating. If so, it would mean that picky eaters can not only be stimulated to accept more diverse food items by exposing them to the taste of food, but also by exposing them to the feel of tactile stimuli.

It is important to stimulate the intake of fruit and vegetables in young children, especially since we know that dietary preferences of young children are quite resistant and prolong even into adulthood (Nicklaus et al., 2005; Skinner et al., 2002). The present studies show that affective evaluation of touching stimuli by hand is related to the evaluation of eating foods in children between 4 and 7.5 years. This stresses the importance of gaining more knowledge about the role of tactile qualities in accepting foods and opens new possibilities in teaching children to appreciate foods.

\section{References}

American Psychiatric Association (2013). DSM 5. Washington, DC: American Psychiatric Association.

Cascio, C., McGlone, F., Folger, S., Tannan, V., Baranek, G., Pelphrey, K. A., et al. (2008). Tactile perception in adults with autism. A multidimensional psychophysical study. Journal of Autism and Developmental Disorders, 38, 127-137.

Coulthard, H., \& Blissett, J. (2009). Fruit and vegetable consumption in children and their mothers. Moderating effects of child sensory sensitivity. Appetite, 52, $410-415$.

Dovey, T. M., Staples, P. A., Gibson, E. L., \& Halford, J. C. G. (2008). Food neophobia and 'picky/fussy' eating in children. A review. Appetite, 50, 181-193.

Dunn, W. (1997). The impact of sensory processing abilities on the daily lives of young children and their families. A conceptual model. Infants and Young Children, 9, 23-35.
Dunn, W. (1999). Sensory profile. User's manual. San Antonio, TX: Psychological Corporation.

Farrow, C. V., \& Coulthard, H. (2012). Relationships between sensory sensitivity, anxiety and selective eating in children. Appetite, 58, 842-846.

Gibson, E. L., Wardle, J., \& Watts, C. J. (1998). Fruit and vegetable consumption, nutritional knowledge and beliefs in mothers and children. Appetite, 31, 205-228.

Jacobi, C., Agras, W. S., Bryson, S., \& Hammer, L. D. (2003). Behavioral validation, precursors, and concomitants of picky eating in childhood. Journal of American Child and Adolescent Psychiatry, 42, 76-84.

Jacobi, C., Schmitz, G., \& Agras, W. S. (2008). Is picky eating an eating disorder? International Journal of Eating Disorders, 41, 626-634.

Lewinsohn, P. M., Holm-Denoma, J. M., Gau, J. M., Joiner, T. E., Striegel-Moore, R., Bear, P., et al. (2005). Problematic eating and feeding behaviors of 36-month-old children. International Journal of Eating Disorders, 38, 208-219.

Lukasewycz, L. D., \& Mennella, J. A. (2012). Lingual tactile acuity and food texture preferences among children and their mothers. Food quality and preference, 26, 58-66.

Mascola, A. J., Bryson, S. W., \& Agras, W. S. (2010). Picky eating during childhood. A longitudinal study to age 11 years. Eating Behaviors, 11, 253-257.

Nicklaus, S., Boggio, V., Chabanet, C., \& Issachou, S. (2005). A prospective study of food variety seeking in childhood, adolescence and early adult life. Appetite, 44, 289-297.

Parush, S., Sohmer, H., Steinberg, A., \& Kaitz, M. (2007). Somatosensory function in boys with ADHD and tactile defensiveness. Physiology E Behavior, 90, 553-558.

Schreck, K. A., Williams, K., \& Smith, A. F. (2004). A comparison of eating behaviors between children with and without autism. Journal of Autism and Developmental Disorders, 34, 433-438.

Skinner, J. D., Carruth, B. R., Bounds, W., \& Ziegler, P. J. (2002). Children's food preferences. A longitudinal analysis. Journal of the American Dietetic Association, 99, 929-937.

Smith, A. M., Roux, S., Naidoo, N. T., \& Venter, D. J. L. (2005). Food choices of tactile defensive children. Nutrition (Burbank, Los Angeles County, Calif.), 21, 14-19.

Szczesniak, A. S. (2002). Texture is a sensory property. Food Quality and Preferences, $13,215-225$.

Wardle, J., \& Cooke, L. (2008). Genetic and environmental determinants of children's food preferences. British Journal of Nutrition, 99, S15-S21.

Zeinstra, G. G., Koelen, M. A., Kok, F. J., \& de Graaf, C. (2010). The influence of preparation method on children's liking for vegetables. Food Quality and Preference, 21, 906-914. 